\title{
Sobre entender, conhecer, escrever (e viver) uma tese
}

\section{About understanding, knowing, writing (and living) a dissertation}

Airton Jordani Jardim Filho ${ }^{1}$ 


\section{Resumo}

presente artigo apresenta questões relativas a escrita de minha tese de doutorado. Dos requisitos básicos para escrever até o foco principal da pesquisa, passando pelo exercício de analisar o trabalho de outros pesquisadores e as relações possíveis com o projeto de minha tese. Traz, ainda, uma breve apresentação de Aloísio Magalhães - precursor do design gráfico no Brasil - abordando uma de suas facetas menos (re)conhecidas, a de artista visual. Através de seus Cartemas Aloísio, apropriou-se do cartão postal para criar uma arte acessível a todos e que convidava o público à interação e ao engajamento. Por fim, de que maneira pretendo trabalhar com a obra de Aloísio com o objetivo de contribuir para a prática diária do professor de artes visuais, por meio dos instrumentos gerados por esta pesquisa.

Palavras-chave: Aloisio Magalhães, Cartemas, Ensino das Artes Visuais, Pesquisa, Doutorado.

\section{Abstract}

This paper presents issues related to writing my doctoral dissertation. From the basic requirements to write until the main focus of the research, through the exercise of analyzing the work of other researchers and the possible links with my dissertation project. It also brings a brief presentation of Aloisio Magalhães - graphic design precursor in Brazil addressing one of its facets less known (recognized): visual artist. Through its Cartemas, Aloisio appropriated the postcard to create an art accessible to all and which invite the public to interaction and engagement. Finally, how I intend to work with the Aloisio's Cartemas in order to contribute to the daily practice of the visual arts' teacher, through the instruments generated by this research.

Keywords: Aloisio Magalhães, Cartemas, Visual Arts Education, Research, Doctorate.

ISSN: 2175-2346

${ }^{1}$ Doutorando em Artes Visuais pelo Programa de Pós-Graduação em Artes Visuais (PPGAV), Centro de Artes (CEART), da Universidade do Estado de Santa Catarina (UDESC). Brasil airtonjordani@gmail.com 
"Disciplina é liberdade,

Compaixão é fortaleza,

Ter bondade é ter coragem"

Renato Russo

$\mathrm{Na}$ epígrafe deste escrito encontram-se reproduzidos três versos da parte final da canção "Há tempos", interpretada pela banda Legião Urbana'. A letra da música foi composta em um formato semelhante a um diálogo entre amigos. Após esses três versos, a composição se encerra com os seguintes: "(ela disse) lá em casa tem um poço, mas a água é muito limpa". Neste verso a palavra 'mas' - conjunção coordenativa adversativa que indica uma oposição de ideias - tem uma curiosa função, dentro da metáfora do poço, empregada pelo autor. Ainda que represente um elo entre ideias contrárias muitas vezes acaba tendo seu uso associado a um sentido pejorativo. "Tal comida é boa, mas engorda" ou "adoro esse ator, mas ele está terrível neste filme". Função curiosa por que Renato Russo a utiliza, sim, como um elemento de ligação entre ideias opostas, mas não como o prenúncio de algo ruim. $\mathrm{A}$ frase é dita por outra pessoa, como se a canção fosse um diálogo. "Ela", que seria uma interlocutora, se refere ao poço como uma metáfora para si mesma, sua própria personalidade. Para se encontrar água é necessário cavar por vários metros abaixo da terra, o que atribui à figura do poço a característica essencial da profundidade. A interlocutora considera sua essência profunda; no entanto, ela é transparente, tal e qual a água muito limpa deve ser.

Os versos da canção servem como paralelo para uma pesquisa de científica, como neste caso, uma tese de doutorado: é necessário que esta seja profunda, mas transparente. Pegando carona nesta mesma metáfora, é fundamental que o pesquisador vá a fundo naquilo que deseja pesquisar, mas deve evitar que isso torne seu texto turvo, opaco. Uma pesquisa complexa não deve resultar em um texto complexo: pelo contrário, a simplicidade ao expressar um conjunto de informações complexas é difícil de se atingir, mas deve ser como a utopia citada por Galeano (2007, p. 310): "Ela está no horizonte - diz Fernando Birri - Me aproximo dois passos, ela se afasta dois passos. Caminho dez passos e o horizonte corre dez passos. Por mais que eu caminhe, jamais a alcançarei. Para que serve a utopia? Serve para isso: para caminhar".

Por ser difícil de se atingir é que a pesquisa demanda tempo, demanda trabalho, demanda, até mesmo, o ócio. O tempo da reflexão, da contemplação, da absorção de tudo aquilo que está sendo visto pela primeira vez e que vai constituir a base do corpus da pesquisa.

A produção intelectual é ardilosa, por ser flutuante e escorregadia. Ela oscila e tem caprichos. O que chamamos de inspiração é a capacidade de reter e ampliar, com um toque próprio e único, um flash ou um insight, uma coisinha de nada que atravessa o nosso pensamento e pode fugir. Porém, boa parte dessa inspiração é fruto da nossa capacidade de concentração, de disciplina, de esforço mental e até de teimosia (Freitas, 2006, p. 220).

Eis uma questão chave sobre a escrita de uma tese: o novo, o desconhecido.

1 "Há Tempos" é a primeira faixa do álbum "As Quatro Estações" da banda brasileira Legião Urbana, lançado em 1989. Assim como as demais canções deste álbum, a letra foi escrita por Renato Russo, vocalista e líder da banda. 
Não se escreve uma tese a partir daquilo que já é conhecido. Escrever uma tese é estar permanentemente encarando o novo, o desconhecido. Porém, para o ser humano, de maneira geral, poucas coisas amedrontam mais do que aquilo que não é conhecido. Não saber o que está por vir é, talvez, nossa maior angústia. Como fugir disso? Não se deve, na verdade. Como afirma Duras (1994, p. 55), "a escrita é o desconhecido. Antes de escrever não sabemos nada acerca do que vamos escrever [...] Se soubéssemos alguma coisa do que vamos escrever, antes de o fazer, antes de escrever, nunca escreveríamos. Não valeria a pena".

A carreira de um pesquisador passa por essas etapas de formação: depois da graduação a pesquisa acadêmica passa por escrever uma dissertação de mestrado e uma tese de doutorado. A "tese é parte indissociável da formação de um pesquisador, e que este será um elemento multiplicador onde quer que ele esteja: na academia, no laboratório, na empresa, no governo, nas comunidades científicas" (Freitas, 2006, p. 216). Ou seja, a tese não termina na ocasião em que o pesquisador a defende em audiência pública para uma banca qualificada. O evento poderia ser classificado como um marco na carreira do pesquisador, momento em que ele publiciza seus quatro anos de pesquisa para toda a sociedade. A partir daí, ele se torna este elemento multiplicador - como citado pela autora - em seus mais diversos campos e ambientes possíveis de trabalho.

Por outro lado, já dizia Isaac Newton: "se vi mais longe foi por estar de pé sobre ombros de gigantes." 2 Nenhum pesquisador chega sozinho a lugar nenhum. Toda pesquisa é fruto da intertextualidade - conforme conceituada por Kristeva, não por acaso intertextualmente baseada nas ideias de Bakhtin ${ }^{3}$. É fundamental, portanto, conhecer o trabalho de outros pesquisadores que fizeram parte deste trajeto anteriormente. Pesquisar outras dissertações, outras teses, permite entender a lógica estrutural de uma pesquisa.

$\mathrm{Na}$ busca por este trajeto, analisei, em conjunto com duas colegas de programa de pós-graduação, a dissertação de mestrado da Profa. Dra. Jociele Lampert de Oliveira, docente do Programa de Pós-Graduação em Artes Visuais (PPGAV), do Centro de Artes (CEART) da Universidade do Estado de Santa Catarina (UDESC). Dentre todas as que foram apresentadas em aula por meus colegas, escolhi a mesma para abordar neste escrito. A razão da escolha é que o grupo do qual eu fazia parte foi o único a apresentar uma pesquisa em área análoga a linha de pesquisa a que sou vinculado no PPGAV, quer seja, Ensino das Artes Visuais. A dissertação, intitulada "Interface artemoda: tecendo um olhar crítico estético do professor de artes visuais" foi apresentada no Programa de Pós-Graduação em Educação, da Universidade Federal de Santa Maria, sob orientação do Prof. Dr. Ayrton Dutra Corrêa, no ano de 2005.

A dissertação era dividida em três partes, sendo elas: "Construindo o contexto investigatório", "Revisitando o aporte teórico" e "Desvelando o caminho percorrido". Faziam parte da primeira parte os capítulos 1 e 2, "Delineando o contexto pesquisado" e "Metodologia da investigação", respectivamente. Na segunda parte estavam

2 Do original em inglês: "If I have seen further it is by standing on the shoulders of Giants". Frase retirada de uma carta de Isaac Newton para Robert Hooke, datada de 5 de fevereiro de 1676; Inspirada numa famosa metáfora (em Latin: nanos Gigantum humeris insidentes) atribuída por John de Salisbury à Bernard de Chartres.

3 Segundo Ramalho e Oliveira (2014), a intertextualidade moderna pode ter seu marco na dialogia e polifonia de Bakhtin. Julia Kristeva amplia as ideias de Bakhtin e apresenta o conceito de intertextualidade. 
inseridos os capítulos 3 e 4, "Artes visuais e moda: territórios entrelaçados" e "Tecendo olhares", respectivamente. Por fim, na terceira e última parte, os capítulos 5 e 6, "Apresentação dos dados coletados e reflexões interpretativas" e as "Considerações finais". O objetivo da pesquisa foi investigar aspectos referentes à discussão da interface arte-moda e suas implicações, para a construção de um olhar crítico-estético do professor de artes visuais na contemporaneidade, onde pensa-se a moda através do âmbito do professor de artes visuais, enfatizando a relevância da contextualização (para o professor e para o aluno). Os objetivos específicos eram: verificar como a moda interfere na percepção do cotidiano dos sujeitos e, ainda, identificar como acontece a interface artística entre artes visuais e moda. As questões de pesquisa eram: "de que maneira o professor de artes visuais tece seu olhar crítico-estético sobre a interface arte-moda?" e "como a interface arte-moda pode favorecer a compreensão crítica do ensino da arte?".

Nas considerações finais, é importante destacar objetivo a objetivo, quais foram. O primeiro objetivo, "pesquisar como se constrói o olhar crítico-estético do professor de Artes Visuais", revelou que a expressão artística passa a ser vista de forma crítica a partir de uma avaliação do processo, do contexto, dos diálogos, propostas e aprofundamento reflexivo por parte do professor. Não somente uma leitura de imagens culturais, mas a constituição de uma educação estética. O conteúdo da arte, quando contextualizada com moda, propõe uma pedagogia interdisciplinar, a interface arte-moda.

Com relação ao objetivo "como acontece a relação de interface entre arte e moda", constatou-se que a interface arte-moda favorece a compreensão crítica no ensino da arte, tanto na forma híbrida ou intertextual, quando relacionada com a história da arte - implicando contextualizações ao conteúdo e ao contexto do aluno. Além disso, é preciso situar um discurso teórico-prático que norteie coerentemente os objetivos da educação que se pretende na contemporaneidade.

Já o projeto proposto para minha tese também se situa no campo do ensino das artes visuais e consiste no desenvolvimento de pesquisa sobre as potencialidades da produção de artistas brasileiros para o ensino de arte. A pesquisa será focado na obra de Aloísio Magalhães, artista e precursor do design gráfico no Brasil. Inegável é a contribuição de Magalhães para a expansão e consolidação do Design no Brasil ${ }^{4}$, não só como uma atividade profissional em si mas, também, como área do conhecimento - já há algum tempo reconhecida pelas estruturas da educação formal no país. Sua faceta menos (re)conhecida, tanto no meio acadêmico, quanto profissional - a de artista visual -, no entanto, foi igualmente inovadora no cenário cultural brasileiro.

Ainda muito jovem, antes mesmo de qualquer aproximação com o Design, Aloísio já demonstrava sua inclinação para as artes visuais. Apesar de possuir trânsito no meio artístico, sua formação como artista foi autodidata e informal: ao ingressar na academia, em 1946, optou pela Faculdade de Direito, da Universidade do Recife. Segundo o próprio Aloísio Magalhães (Taborda \& Leite, 2003, p. 27), "quem é que não fazia direito naquela época? Era o primeiro sinal de bom senso, quer dizer, bom senso de desejo de uma projeção política, intelectual...". O que se viu, posteriormente,

4 Tal reconhecimento pode ser atestado pelo Decreto Presidencial de 19 de outubro de 1998, que institui a data de 5 de novembro - aniversário de Aloísio Magalhães - como o Dia Nacional do Design (Presidência da República, 2016). 
é que a faculdade de Direito reforçou ainda mais sua formação humanística e, por consequência, influenciou positivamente sua trajetória artística.

Aloísio graduou-se em Direito em 1950 e, um ano depois, teve uma passagem de estudos pela Europa, como bolsista do governo francês, na área de artes visuais. Apesar disso, retornou para Recife depois de dois anos, sem ter conseguido encontrar o que procurava. Em matéria publicada no jornal Última Hora, em março de 1952, ao ser questionado sobre o que gostaria ter encontrado em Paris, afirmou: "Mestres que me ensinassem o que não sei. Pensei que poderia trabalhar com alguns dos pintores que admiro, porém não foi possível. Inclusive no que diz respeito àqueles que, como Léger ${ }^{5}$ ou Lhote ${ }^{6}$, têm academia, não ensinam como eu entendo" (Taborda \& Leite, 2003, p. 35). Em 1954, fundou - com Gastão de Holanda, Orlando da Costa Ferreira, José Laurenio de Melo, João Cabral de Melo Neto e Ariano Suassuna - uma gráfica experimental chamada "O Gráfico Amador": apesar de seus apenas sete anos de existência, a iniciativa foi de fundamental importância para as origens da tipografia moderna brasileira, e para diversas inovações em termos de ilustração, diagramação e impressão dos mais variados tipos de material gráfico (Funarte, 1982; Lima, 2014).

Além disso, Aloísio desenvolveu diversos outros trabalhos no campo das artes visuais, de pintura a escultura, passando pela gravura e desenho, tendo exposto seus trabalhos nos Estados Unidos e Europa. Magalhães sempre caracterizou sua produção artística por uma mescla de sofisticação intelectual e manifestação popular. Sua ligação com a cultura popular, estendeu-se por toda sua vida, tanto como artista, quanto como designer, culminando com influências percebidas ao longo da sua carreira política, em diversos cargos que ocupou no antigo Ministério da Educação e Cultura (MEC), chegando a ser nomeado Secretário Nacional de Cultura, em 1981 um ano antes de sua morte.

Uma de suas principais - se não a mais importante - contribuição artística foi a criação dos Cartemas. A reflexão a respeito da produção, pela Casa da Moeda brasileira, das cédulas de cruzeiros por ele idealizadas ${ }^{7}$, foi o ponto de partida para uma de suas mais marcantes contribuições para o campo das artes visuais (Anjos, 2002). A observação do efeito obtido pela impressão de várias cédulas em uma folha de papel maior foi fundamental para que Magalhães concebesse o que logo adiante seria batizado como Cartema. Neologismo criado pelo filólogo Antônio Houaiss, a palavra cartema designa uma composição visual construída a partir de várias cópias de determinada imagem, tendo como suporte a técnica da colagem.

Tais imagens eram, quase sempre, cartões postais convencionais, com retratos de paisagens, cenas cotidianas e fotografias diversas. Os postais eram colados lado a lado, em posições diferentes, dando ao conjunto uma nova unidade visual, face à continuidade das imagens montadas repetidamente em módulos simétricos, forte-

\footnotetext{
5 Léger, Fernand (1881-1955). Pintor francês. [...] A influência de Léger sobre os artistas da época foi abrangente e diversificada. Há um museu com seu nome em Biot, na França. (Chilvens, 2001, p. 299)

6 Lhote, André (1885-1962). Pintor, escultor e teórico da arte francês. [...] Exerceu ampla influência sobre artistas mais jovens, tanto franceses como estrangeiros, através de sua própria academia de arte, a Académie Montparnasse, inaugurada em 1922. (Chilvens, 2001, p. 306)

7 Em 1966, através de um concurso fechado para artistas gráficos promovido pelo governo brasileiro, Magalhães foi escolhido para iniciar o processo de nacionalização da produção de dinheiro. Até então o país não tinha autonomia na produção de seu papel moeda, dependendo de fornecedores estrangeiros como o American Bank Note e Thomas de La Rue. Vencido o concurso por Aloísio Magalhães, em 1967 foi lançado o novo Padrão Monetário Brasileiro. Pela primeira vez, as cédulas brasileiras tinham um desenho brasileiro. Estava iniciado o processo para que a Casa da Moeda do Brasil passasse a ser a única fabricante do dinheiro brasileiro (Taborda \& Leite, 2003).
} 
mente baseada na padronagem criada por esta composição vista como um todo. A descrição não corresponde à potencia da obra em si, pois pode levar a crer que existe algo de acidental ou, até mesmo, aleatório em sua criação. No entanto, Aloísio Magalhães (Funarte, 1982, p. 9) já afirmava que, "embora simples, o cartema não é um achado. Tem toda a vivência e o treinamento de um olho atento a tudo." Aloísio, na mesma publicação, afirmava ainda, à época, que "a arte anda meio trágica, densa, sufocada. Perde diariamente o caráter lúdico e a graça. O cartema restitui ao espectador a alegria perdida. Ninguém fica indiferente". Ou seja, contextualizando a fala e a obra de Guimarães, é possível perceber que os cartemas surgiram num cenário artístico brasileiro no qual artistas buscavam uma relação mais participativa entre a obra e o público.

Empenhado em tornar os cartemas uma proposição estética acessível a qualquer pessoa interessada - concretizando, dessa maneira, seu desejo de fazer da arte uma experiência coletiva -, Aloísio Magalhães divulgou, em catálogo de exposição, os procedimentos técnicos necessários a sua criação. Aproximava-se, de modo original, de propostas correntes na arte brasileira ao longo da década de 70 , as quais buscavam a participação do público na criação de múltiplos (como Nelson Leirner), na ativação do sentido nas obras (Lygia Clark) ou mesmo em sua inserção em rotas alternativas de circulação artística (a arte postal, por exemplo) (Anjos, 2002, p. 102).

Uma iniciativa que buscava não apenas uma participação maior do público, em seus cartemas, Aloísio apropriou-se do cartão postal e criou uma obra não apenas acessível a todos, mas que objetivava - assim como as obras de seus contemporâneos Lygia Clark, Helio Oiticica, Nelson Leirner e tantos outros - convidar o público à interação e ao engajamento. Ainda nos anos 1970, o artista buscava o que ainda hoje, na arte contemporânea, segue sendo relevante: provocar a reflexão a respeito da experiência na qual está envolvido, levar o foco para a interação entre público e obra e, também, propor um trabalho que seja, em última análise, uma construção coletiva. Em sua etapa experimental, minha tese se utilizará de reproduções dos cartemas de Aloisio Magalhães tanto quanto se apropriará da técnica empregada para sua confecção, trazendo a experiência estética proposta pelo artista nos anos 1970 para os dias de hoje, em salas de aula.

Assim como dissertação analisada, o foco principal de minha tese é o professor de artes visuais e sua prática diária: de que maneira pode a tese contribuir para sua atividade, buscando o empoderamento do professor utilizando os instrumentos gerados pela pesquisa como suporte para sua atividade cotidiana, auxiliando na aplicação da proposta triangular de Barbosa (2009) e Hernandez (2000). Por fim, retomo os versos da epígrafe deste texto, mais uma vez traçando um paralelo entre "Há tempos" e a tese: "disciplina é liberdade, compaixão é fortaleza, ter bondade é ter coragem". Ser disciplinado é fundamental para ser livre, em um mundo competitivo, onde o individualismo é a regra, para se ter compaixão é necessário muita força e, acima de tudo, muita coragem para ser bom. Freitas (2006, p. 215) afirma: "viver uma tese é uma arte!", mas ser pesquisador não deve ser um mero emprego (como disse a própria autora), logo é possível concluir: não apenas a tese, mas viver - como um todo - é uma arte! 


\section{Referências}

ANJOS, M. Coleções de sentidos. In: CHIARELLI, T. apropriações | coleções: catálogo da exposição. Porto Alegre: Santander Cultural. 2002.

BARBOSA, Ana Mae. A Imagem no ensino da arte: anos 1980 e novos tempos. São Paulo: Perspectiva, 2009.

CHILVENS, I. Dicionário Oxford de Arte. 2a. Ed. São Paulo: Martins Fontes, 2001.

DURAS, M. Escrever. Trad. de Rubens Figueiredo. São Paulo: Ed. Rocco, 1994.

FREITAS, M. E. Viver a tese é preciso! In: Bianchetti, L.; Machado, A. M. N. A bússola do escrever. Florianópolis: Ed. Cortez \& Editoria Vozes, 2005.

FUNARTE. Cartemas: A Fotografia como Suporte de Criação. Rio de Janeiro: Fundação Nacional de Arte/Núcleo de Fotografia, 1982.

GALEANO, E. As palavras andantes. 5. ed. Porto Alegre: L\&PM, 2007.

HERNÁNDEZ, F. Cultura visual, mudança educativa e projeto de trabalho. Porto Alegre: Ed. Artmed, 2000.

LIMA, G. C. O Gráfico Amador. Rio de Janeiro: Verso Brasil Ed, 2014.

MAZZOTTI, A. J. A. A "revisão da bibliografia em teses e dissertações: meus tipos inesquecíveis - o retorno. In: Bianchetti, L.; Machado, A. M. N. A bússola do escrever. Florianópolis: Ed. Cortez \& Editoria Vozes, 2005.

OLIVEIRA. Título: subtítulo. Ano da defesa. Número de folhas. Categoria (Nível e área de concentração) - Instituição da defesa, Cidade da defesa.

PRESIDÊNCIA DA REPÚBLICA. Decreto de 19 de outubro de 1998. Disponível em: < http://www.planalto.gov.br/ccivil_03/dnn/Anterior\%20a\%202000/1998/Dnn7508. htm >. Acesso em: abr. 2016.

RAMALHO E OLIVEIRA, S. R. Sentidos dos hiatos na intertextualidade (Manuscrito não publicado). In: Encontro da Anpap - "Ecossistemas Artísticos", 23., 2014, Belo Horizonte.

TABORDA, F.; LEITE, J. S. A Herança do Olhar: o Design de Aloísio Magalhães. Rio de Janeiro: Artviva/SENAC. 2003. 